\title{
Thermal properties of wood-based panels: specific heat determination
}

\author{
Lukasz Czajkowski ${ }^{1}$ • Wiesław Olek ${ }^{1}$ • \\ Jerzy Weres ${ }^{2} \cdot$ Ryszard Guzenda $^{1}$
}

Received: 15 June 2015/Published online: 26 February 2016

(C) The Author(s) 2016. This article is published with open access at Springerlink.com

\begin{abstract}
Ensuring reliability of data on thermal properties of wood-based panels is important for manufacturing processes, especially when it is recommended to shorten the cooling phase and stack the panels in hot conditions. Prediction of the heat transfer during cooling phase and normal or hot stacking based on accurate data is essentially important for attaining panels of required properties. The thermal properties are also required when designing houses, especially low-energy or passive ones. Therefore, a water calorimeter was adequately designed and constructed to ensure improvement in the accuracy of the specific heat measurements. The calorimeter was used to determine the specific heat. The attained accuracy estimated by the relative error was significantly increased, and the error values were less than $2 \%$ for all types of the investigated particleboard and OSB. In case of low-density fiberboard (LDF), the maximum value of the relative error did not exceed $4 \%$. It was also shown that high accuracy required for the specific heat measurements was achieved for experiments in which high-mass samples were used, in contrast to measurements for such samples in traditional DSC systems. The results for the specific heat were within the range from 1420 to $1450 \mathrm{~J} / \mathrm{kg} \mathrm{K}$ for LDF and all types of particleboard. The effect of the investigated material density on the specific heat was not found. The only exception was in case of OSB for which the specific heat was ca. $1550 \mathrm{~J} / \mathrm{kg} \mathrm{K}$, and it was approximately $100 \mathrm{~J} / \mathrm{kg} \mathrm{K}$ higher when compared to other panels.
\end{abstract}

Łukasz Czajkowski

lukasz.czajkowski@up.poznan.pl

1 Faculty of Wood Technology, Poznań University of Life Sciences, ul. Wojska Polskiego 28, 60-637 Poznań, Poland

2 Faculty of Agriculture and Bioengineering, Poznań University of Life Sciences, ul. Wojska Polskiego 28, 60-637 Poznań, Poland 


\section{Introduction}

Credible data on thermal properties of wood-based panels are of special significance also during manufacturing processes, e.g., for controlling the cooling phase which is required before stacking materials already produced. Cooling of panels is especially important in the case of composites bonded with urea-formaldehyde or melamineurea-formaldehyde resins as temperature of a stack as high as $65-70{ }^{\circ} \mathrm{C}$ may result in hydrolysis of the resins, and therefore, it can lead to the reduction in the bonding strength of particles within panels (e.g., Chapman 2006; Irle and Barbu 2010). However, in the case of panels bonded with phenol-formaldehyde resins it is often recommended to shorten the cooling phase and stack the panels in hot conditions. The hot stacking is used to complete the curing process of phenol-formaldehyde resins, especially in the core layers of the panels (e.g., Carvalho et al. 2010). Therefore, the accurate prediction of heat transfer during cooling phase as well as during normal or hot stacking has special importance for obtaining the required properties of the panels.

High accuracy of thermal properties of wood-based panels is also required when designing houses, especially low-energy or passive ones. The proper application of materials forming thermal envelope of a building is one of the most important problems which is faced during the design process (e.g., Kosny et al. 2014; Upton et al. 2008). The primary goal of the thermal envelope is to reduce heat losses of a building in winter and heat gains in summer. The heat transfer reduction can be relatively easily obtained; however, inaccurate data on the thermal properties of materials may cause unfavorable and uncontrolled local increase in heat transfer, which is usually called heat bridges (Piot et al. 2011). The phenomenon is usually associated with water condensation at surfaces with low temperature. It results in dramatic decrease in insulating properties of the materials due to increase in their moisture content. Moreover, the process is self-propelling as the increase in moisture content causes further increase in thermal conductivity of the materials.

The thermal properties of wood-based panels which are required for heat transfer calculations usually consist of specific heat and thermal conductivity. The two properties are, however, determined with different experimental methods. The specific heat is traditionally measured with calorimetric methods (e.g., Baryeh 1997), while the thermal conductivity values are obtained by the application of various methods based on principles of steady-state or transient heat transfer (e.g., Sonderegger and Niemz 2009; Zhou et al. 2013). In the last decades, the development of the calorimetric methods resulted in constructing automated systems for thermodynamic analysis of materials based on the technique of differential scanning calorimetry (DSC). The most important disadvantage of the DSC systems, as applied for investigating wood-based panels, is mass of samples usually being less than $100 \mathrm{mg}$ (e.g., Menczel et al. 2009; Wolfinger et al. 2001; Ghazi Wakili et al. 2003). The low mass of samples has special significance in relation to large inhomogeneity of particles forming particleboard and OSB. Therefore, special procedures of the material homogenization should be performed before forming samples (e.g., Gupta et al. 2003). The required homogenization of 
the material is usually hard to perform for wood-based panels. Another difficulty related to preparation of samples is evacuation of air from a sample pan. The DSC application for investigating hygroscopic materials implies intensive water evaporation from the investigated samples (e.g., Li et al. 2013). It results in uncontrolled changes in determined values for successive repetitions of measurements. Consequently, the requirement for investigation of oven dry samples is formulated (e.g., Gupta et al. 2003; Li et al. 2013). The disadvantages of the DSC application can be overcome when using traditional calorimetric methods.

The objective of the study was to determine the specific heat of wood-based panels. In order to increase the accuracy of the specific heat measurements, the water calorimeter was properly designed and manufactured.

\section{Materials and methods}

The requirements for accurate measurements of specific heat of wood-based panels practically cannot be met by an application of commercially available calorimeters. Therefore, in the present study a calorimeter was designed and constructed. Woodbased panels are characterized by relatively low heat capacity which results in small amount of heat released during calorimetric measurements. It implies the requirement for the application of samples of high mass. Another problem related to the calorimetric measurements is a proper selection of a medium used for exchanging heat between a sample and an inner cup of a calorimeter. It was decided in the reported study to use water as the medium as it ensured relatively intensive heat transfer and reasonably short time for obtaining the equilibrium temperature of the system. The short time has an additional merit of the system as it reduces heat losses and increases accuracy of measurements. However, the application of water in the calorimetric system has an important drawback, i.e., water easily soaks into hygroscopic porous materials and changes their thermal properties. Therefore, surfaces of a sample have to be sealed against water penetration. Heat shrinking membrane was applied in order to provide the sealing. The preliminary analysis of heat transfer was performed for the calorimetric system, and it was assumed that the minimum temperature increase in the calorimetric system has to be equal to $2 \mathrm{~K}$ for the initial temperature of a sample and water equal to 80 and $20{ }^{\circ} \mathrm{C}$, respectively. The assumption resulted in estimating the sample size of $0.7 \mathrm{dm}^{3}$.

Design of the calorimetric system was started with formulating the steady-state heat balance equation. It was assumed that a sample and sealing membrane were releasing heat in the system, while water and the inner cup were gaining it. The heat balance equation was transformed, and the following formula was used to calculate specific heat of investigated wood-based panels:

$$
c=\frac{\left(m_{\mathrm{a}} \cdot c_{\mathrm{a}}+m_{\mathrm{H}_{2} \mathrm{O}} \cdot c_{\mathrm{H}_{2} \mathrm{O}}\right) \cdot\left(t_{\mathrm{e}}-t_{\mathrm{ic}}\right)+m_{\mathrm{m}} \cdot c_{\mathrm{m}} \cdot\left(t_{\mathrm{e}}-t_{\mathrm{is}}\right)}{m \cdot\left(t_{\mathrm{is}}-t_{\mathrm{e}}\right)}
$$

where $c(\mathrm{~J} / \mathrm{kg} \mathrm{K})$ - specific heat of investigated material; $c_{\mathrm{a}}(\mathrm{J} / \mathrm{kg} \mathrm{K})$ - specific heat of aluminum; $c_{\mathrm{H}_{2} \mathrm{O}}(\mathrm{J} / \mathrm{kg} \mathrm{K})$ - specific heat of water; $c_{\mathrm{m}}(\mathrm{J} / \mathrm{kg} \mathrm{K})$ - specific heat of 
shrinking membrane; $m(\mathrm{~kg})$ —mass of investigated material (mass of sample); $m_{\mathrm{a}}$ $(\mathrm{kg})$ - mass of aluminum (calorimeter inner cup with a stirring rod); $m_{\mathrm{H}_{2} \mathrm{O}}(\mathrm{kg})$ mass of water; $m_{\mathrm{m}}(\mathrm{kg})$ - mass of shrinking membrane; $t_{\mathrm{e}}\left({ }^{\circ} \mathrm{C}\right)$ - equilibrium temperature of the calorimetric system; $t_{\text {ic }}\left({ }^{\circ} \mathrm{C}\right)$-initial temperature of the calorimeter with water; $t_{\text {is }}\left({ }^{\circ} \mathrm{C}\right)$-initial temperature of the investigated material (sample).

The absolute error (uncertainty) of the specific heat determination $(\Delta c)$ was calculated by application of the total differential method (e.g., Taylor 1997). It was less than or equal to the sum of absolute values of specific heat partial derivatives with respect to measured quantities as multiplied by uncertainties of individual measurements. During the experiments, the following quantities were assumed to be measured, i.e., mass $m, m_{\mathrm{a}}, m_{\mathrm{H}_{2} \mathrm{O}}, m_{\mathrm{m}}$ as well as temperature $t_{\mathrm{e}}, t_{\mathrm{ic}}, t_{\mathrm{is}}$. Therefore, the formula for calculating the absolute error is given as

$$
\begin{aligned}
\Delta c & \leq\left|\frac{\partial c}{\partial m}\right| \Delta m+\left|\frac{\partial c}{\partial m_{\mathrm{a}}}\right| \Delta m_{\mathrm{a}}+\left|\frac{\partial c}{\partial m_{\mathrm{H}_{2} \mathrm{O}}}\right| \Delta m_{\mathrm{H}_{2} \mathrm{O}}+\left|\frac{\partial c}{\partial m_{\mathrm{m}}}\right| \Delta m_{\mathrm{m}} \\
& +\left|\frac{\partial c}{\partial t_{\mathrm{e}}}\right| \Delta t_{\mathrm{e}}+\left|\frac{\partial c}{\partial t_{\mathrm{ic}}}\right| \Delta t_{\mathrm{ic}}+\left|\frac{\partial c}{\partial t_{\mathrm{is}}}\right| \Delta t_{\mathrm{is}} .
\end{aligned}
$$

The performed analysis of the mathematical structure of Eq. (2) clearly showed that the absolute error of the specific heat determination mainly depends on uncertainty of temperature measurements. However, in order to estimate the uncertainty values of specific measurements the relative error of the quantity determination was also defined

$$
\delta c=\frac{\Delta c}{c} \cdot 100 \%
$$

The estimation of uncertainties of the specific heat determination was performed for the following configuration of the experimental system: the initial temperature of a sample was determined with the type $\mathrm{K}$ thermocouple of the uncertainty of $0.1 \mathrm{~K}$, the initial temperature of the calorimeter with water and the equilibrium temperature of the calorimetric system was determined with the type $\mathrm{J}$ thermocouple of the uncertainty of $0.02 \mathrm{~K}$, and mass of all components of the calorimetric system was measured with uncertainty of $0.0001 \mathrm{~kg}$. It was found that the relative error $\delta c$ should not exceed $4 \%$ for such specification of the system. Another option of the experimental system was analyzed-the type $\mathbf{J}$ thermocouples were replaced with the type $\mathrm{K}$ ones. It resulted in unacceptable increase in the relative error $\delta c$ to ca. $17 \%$, i.e., almost five times higher values of the error were estimated. Therefore, the importance of applying the type $\mathrm{J}$ thermocouples was clearly demonstrated.

Experimental material was obtained from the following wood-based panels: (a) commercial three-layer particleboard of the thickness of $18 \mathrm{~mm}$ and mean oven dry density of $634 \mathrm{~kg} / \mathrm{m}^{3}$ (coded as PB1), (b) normal-density laboratory-made onelayer particleboard of reduced density profile of the thickness of $26 \mathrm{~mm}$ and mean oven dry density of $754 \mathrm{~kg} / \mathrm{m}^{3}$ (coded as PB2), (c) high-density laboratory-made one-layer particleboard of reduced density profile of the thickness of $10 \mathrm{~mm}$ and mean oven dry density of $973 \mathrm{~kg} / \mathrm{m}^{3}$ (coded as PB3), (d) laboratory-made one-layer low-density fiberboard of the thickness of $20 \mathrm{~mm}$ and mean oven dry density of 
$256 \mathrm{~kg} / \mathrm{m}^{3}$ (coded as LDF) and (e) commercial oriented strand boards of the thickness of $15 \mathrm{~mm}$ and mean oven dry density of $619 \mathrm{~kg} / \mathrm{m}^{3}$ (coded as OSB). The material was firstly equilibrated in laboratory conditions, i.e., at temperature of $20{ }^{\circ} \mathrm{C}$ and relative humidity of $50 \%$, and it resulted in moisture content of 6-7\%.

Then, round sheets of $80 \mathrm{~mm}$ diameter were cut from all types of the investigated material. The sheets were used to form samples in the shape of cylinders of a height of $135 \mathrm{~mm}$. Two type $\mathrm{K}$ thermocouples were mounted in the center and at the surface of each sample. The thermocouples were used to control the temperature distribution in samples and to measure the equilibrium temperature of the samplecalorimeter system. The samples were covered with heat shrinkable membrane of specific heat, which was accounted for in the heat balance of the system.

The performed analysis of uncertainties enabled to construct the cup of the calorimeter. It was in the shape of a cylinder with an inner hole of $4 \mathrm{dm}^{3}$ volume. The cup was made of the aluminum alloy PA6 characterized by specific heat of $860 \mathrm{~J} / \mathrm{kg} \mathrm{K}$ for temperature range of $17-21^{\circ} \mathrm{C}$. The same material was used for making a stirring rod. Mass of the cup and the stirring rod $\left(m_{\mathrm{a}}\right)$ was equal to $4.3002 \mathrm{~kg}$. After mounting the type $\mathrm{J}$ and $\mathrm{K}$ thermocouples, the cup was tightly placed in a styrofoam block. The minimum thickness of the styrofoam insulation was $12 \mathrm{~cm}$. The applied insulation effectively reduced heat losses of the calorimetric system. The general view of the calorimeter with a sample being placed into water is depicted in Fig. 1.

Before starting the calorimetric experiments, samples were covered with shrinkable membrane and heated up for $18 \mathrm{~h}$ in order to obtain the uniform initial temperature of $98^{\circ} \mathrm{C}$. Simultaneously the calorimeter cup was filled with a portion

Fig. 1 General view of the water calorimeter: 1 thermocouples type J and K, 2 sample sealed with heat shrinking membrane, 3 -inner aluminum cup, 4-styrofoam block

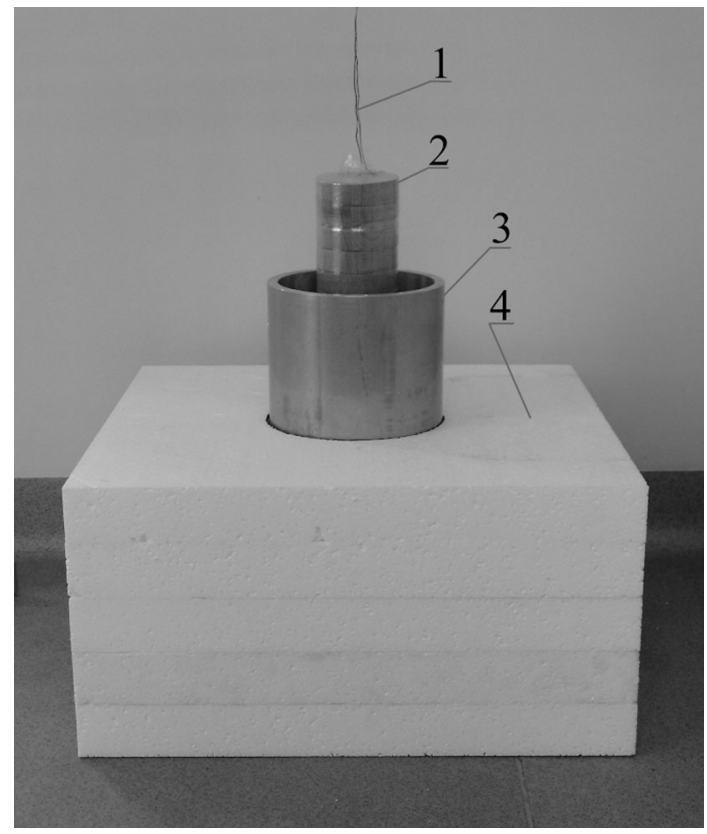


of distilled water of mass $m_{\mathrm{H}_{2} \mathrm{O}}$. The water in the cup was frequently stirred, and after $2 \mathrm{~h}$, the initial temperature of the calorimeter with water was obtained. Next, a sample with uniform initial temperature was placed in the cup and immersed in water. The top of the calorimeter was covered with styrofoam insulation. Water in the cup was again frequently stirred, and measurements of temperature $t_{e}$ were started. The equilibrium temperature was usually obtained after $3 \mathrm{~h}$. The experimental procedure was repeated five times for each type of the investigated material.

\section{Results}

The results of the performed calorimetric experiments are presented in Table 1. The specific heat values of all investigated materials were calculated with Eq. (1). The obtained results were supplemented by the absolute and relative errors (Table 1).

The mean values of specific heat of LDF, PB1, PB2 and PB3 were similar and varying from 1420 to $1450 \mathrm{~J} / \mathrm{kg} \mathrm{K}$ despite different density, moisture content and resin content of the investigated panels. The obtained mean value of the specific heat of OSB was equal to $1552 \mathrm{~J} / \mathrm{kg} \mathrm{K}$ and higher as compared to other investigated materials. Moreover, the analysis of the error values clearly demonstrated that the assumed high accuracy of the specific heat measurements was obtained.

The individual and mean values of the specific heat were supplemented by the estimated values of absolute and relative errors (Table 1). The analysis of the observed errors showed that the inaccuracy of the specific heat measurements increased with the decrease in mass of samples of the investigated materials. The highest values of absolute and relative errors of ca. $50 \mathrm{~J} / \mathrm{kg} \mathrm{K}$ and $4 \%$ were found for LDF which was characterized by the lowest density. Contrary to that, the lowest values of the errors of ca. $20 \mathrm{~J} / \mathrm{kg} \mathrm{K}$ and $1.5 \%$ were found for particleboard PB3, which was characterized by the highest density. The observations clearly supported the earlier assumption of performing the measurements for samples with high mass.

The measured values of specific heat were also compared to the data available in the literature. Nanassy and Szabo (1978) reported data on the specific heat for wood-based panels characterized by density and moisture content being similar to the panels investigated in the present study. It was found that the measured values were ca. $100 \mathrm{~J} / \mathrm{kg} \mathrm{K}$ lower than the results discussed by Nanassy and Szabo (1978). Baryeh (1997) discussed the influence of density of wood-based panels on their specific heat. It was clearly shown that the specific heat values increased with the density increase. It is contrary to the current observations reported in Table 1 where the density had no significant influence on the measured values. Therefore, the data reported by Baryeh (1997) were much higher as compared to the results presented in Table 1 . The differences were equal to ca. $500 \mathrm{~J} / \mathrm{kg} \mathrm{K}$ for density of ca. $600 \mathrm{~kg} / \mathrm{m}^{3}$ (e.g., PB1) as well as ca. $1600 \mathrm{~J} / \mathrm{kg} \mathrm{K}$ for density of ca. $1000 \mathrm{~kg} / \mathrm{m}^{3}$ (e.g., PB3).

The specific heat data of wood-based panels are also given in the form of empirical models being functions of density and, in some cases, temperature. Again the comparison was made between the results presented in Table 1 and the specific heat values calculated from the models reported by Ward and Skaar (1963) as well as by TenWolde et al. (1988). Practically insignificant differences were noticed 
Table 1 Measured values of the heat balance components together with calculated specific heat, absolute error and relative error

\begin{tabular}{|c|c|c|c|c|c|c|c|c|c|c|}
\hline Codes & $\begin{array}{l}m_{\mathrm{H}_{2} \mathrm{O}} \\
(\mathrm{kg})\end{array}$ & $\begin{array}{l}m \\
(\mathrm{~kg})\end{array}$ & $\begin{array}{l}m_{\mathrm{m}} \\
(\mathrm{kg})\end{array}$ & $\begin{array}{l}t_{\text {ic }} \\
\left({ }^{\circ} \mathrm{C}\right)\end{array}$ & $\begin{array}{l}t_{\text {is }} \\
\left({ }^{\circ} \mathrm{C}\right)\end{array}$ & $\begin{array}{l}t_{\mathrm{e}} \\
\left({ }^{\circ} \mathrm{C}\right)\end{array}$ & $\begin{array}{l}\Delta T \\
(\mathrm{~K})\end{array}$ & $\begin{array}{l}c \\
(\mathrm{~J} / \mathrm{kg} \mathrm{K})\end{array}$ & $\begin{array}{l}\Delta c \\
(\mathrm{~J} / \mathrm{kg} \mathrm{K})\end{array}$ & $\begin{array}{l}\delta c \\
(\%)\end{array}$ \\
\hline \multirow[t]{6}{*}{ PB1 } & 3.5283 & 0.3894 & 0.0120 & 17.52 & 98.0 & 19.94 & 2.42 & 1434 & 27.28 & 1.90 \\
\hline & 3.3212 & 0.3792 & 0.0150 & 17.88 & 98.8 & 20.38 & 2.50 & 1434 & 26.69 & 1.86 \\
\hline & 3.3410 & 0.3781 & 0.0146 & 18.28 & 98.6 & 20.76 & 2.48 & 1445 & 27.08 & 1.87 \\
\hline & 3.3560 & 0.3787 & 0.0124 & 17.88 & 98.2 & 20.34 & 2.46 & 1442 & 27.10 & 1.88 \\
\hline & 3.2554 & 0.3792 & 0.0129 & 17.22 & 99.0 & 19.80 & 2.58 & 1449 & 26.08 & 1.80 \\
\hline & & & & & & & $\begin{array}{l}\text { Mean } \\
\text { value }\end{array}$ & 1441 & 26.85 & 1.86 \\
\hline \multirow[t]{6}{*}{ PB2 } & 3.3478 & 0.4285 & 0.0112 & 16.96 & 99.3 & 19.76 & 2.80 & 1424 & 23.64 & 1.66 \\
\hline & 3.5860 & 0.4245 & 0.0112 & 17.22 & 99.4 & 19.84 & 2.62 & 1421 & 25.00 & 1.76 \\
\hline & 3.3116 & 0.4262 & 0.0138 & 17.60 & 98.9 & 20.38 & 2.78 & 1421 & 23.88 & 1.68 \\
\hline & 3.3322 & 0.4281 & 0.0124 & 17.64 & 99.1 & 20.42 & 2.78 & 1423 & 23.83 & 1.68 \\
\hline & 3.3008 & 0.4300 & 0.0127 & 17.82 & 99.2 & 20.64 & 2.82 & 1428 & 23.63 & 1.66 \\
\hline & & & & & & & $\begin{array}{l}\text { Mean } \\
\text { value }\end{array}$ & 1423 & 24.00 & 1.69 \\
\hline \multirow[t]{6}{*}{ PB3 } & 3.5214 & 0.5784 & 0.0106 & 17.34 & 96.0 & 20.82 & 3.48 & 1454 & 19.81 & 1.36 \\
\hline & 3.5266 & 0.5784 & 0.0106 & 17.36 & 98.1 & 20.92 & 3.56 & 1451 & 19.33 & 1.33 \\
\hline & 3.5148 & 0.5784 & 0.0106 & 17.08 & 98.3 & 20.66 & 3.58 & 1446 & 19.16 & 1.33 \\
\hline & 3.5508 & 0.5784 & 0.0106 & 17.40 & 97.1 & 20.90 & 3.50 & 1452 & 19.66 & 1.35 \\
\hline & 3.2932 & 0.5407 & 0.0101 & 17.46 & 93.5 & 20.76 & 3.30 & 1445 & 20.73 & 1.43 \\
\hline & & & & & & & $\begin{array}{l}\text { Mean } \\
\text { value }\end{array}$ & 1450 & 19.74 & 1.36 \\
\hline \multirow[t]{6}{*}{$\mathrm{LDF}$} & 3.1434 & 0.1878 & 0.0139 & 17.88 & 97.2 & 19.18 & 1.30 & 1409 & 49.81 & 3.53 \\
\hline & 3.3404 & 0.1864 & 0.0129 & 17.98 & 95.8 & 19.20 & 1.22 & 1430 & 53.41 & 3.73 \\
\hline & 3.1918 & 0.1870 & 0.0126 & 17.76 & 88.5 & 18.90 & 1.14 & 1416 & 56.50 & 3.99 \\
\hline & 3.2936 & 0.1888 & 0.0129 & 18.20 & 97.6 & 19.46 & 1.26 & 1414 & 51.18 & 3.62 \\
\hline & 3.2936 & 0.1867 & 0.0128 & 17.26 & 97.8 & 18.54 & 1.28 & 1433 & 51.06 & 3.56 \\
\hline & & & & & & & $\begin{array}{l}\text { Mean } \\
\text { value }\end{array}$ & 1420 & 52.39 & 3.69 \\
\hline \multirow[t]{6}{*}{ OSB } & 3.3444 & 0.4144 & 0.0139 & 18.00 & 98.1 & 20.86 & 2.86 & 1542 & 25.28 & 1.64 \\
\hline & 3.3560 & 0.4144 & 0.0139 & 17.26 & 98.3 & 20.20 & 2.94 & 1573 & 25.13 & 1.60 \\
\hline & 3.3756 & 0.4120 & 0.0125 & 17.72 & 97.7 & 20.50 & 2.78 & 1523 & 25.55 & 1.68 \\
\hline & 3.3450 & 0.4118 & 0.0122 & 17.64 & 98.1 & 20.54 & 2.90 & 1572 & 25.38 & 1.61 \\
\hline & 3.2994 & 0.4139 & 0.0130 & 16.66 & 98.0 & 19.60 & 2.94 & 1550 & 24.73 & 1.60 \\
\hline & & & & & & & $\begin{array}{l}\text { Mean } \\
\text { value }\end{array}$ & 1552 & 25.21 & 1.62 \\
\hline
\end{tabular}

when comparing the data. However, it has to be emphasized that the model reported by TenWolde et al. (1988) was originally developed for solid wood. It has special importance when considering the observation reported by Kamke and Zylkowski (1989) that the thermal properties of wood-based panels are different from the solid wood of which the panels were made. Therefore, special caution has to be given 
when applying such empirical models as it can significantly influence the accuracy of specific heat values calculated from the model.

Resin type and content are another possible factor influencing specific heat of wood-based panels. However, these two parameters are frequently skipped when considering thermal properties of the panels. It is primarily due to problems in obtaining credible data on the resin content. Therefore, the thermal properties of wood-based panels are often adapted from the properties of solid wood. For instance, Kawasaki and Kawai (2006) assumed the specific heat as equal to $1500 \mathrm{~J} / \mathrm{kg} \mathrm{K}$ regardless of wood-based panels or solid wood and their density.

The evaluation of the credibility of the measured values of specific heat can only be made when applying the data to model transient heat transfer in wood-based panels and comparing results of modeling to experiments. However, it can be performed when determining thermal conductivity of the investigated panels (Czajkowski et al. 2016).

\section{Conclusion}

1. The designed and constructed calorimeter enabled to perform measurements of the specific heat of wood-based panels with accuracy estimated by the relative error being less than $2 \%$ for all types of the investigated particleboard and OSB. In the case of LDF, the maximum value of the relative error did not exceed $4 \%$.

2. It was clearly presented that the required high accuracy of the specific heat measurements could be obtained for experiments made with samples of high mass. It was in contrast to measurements traditionally made with samples used in DSC systems.

3. The measured values of the specific heat were within the range from 1420 to $1450 \mathrm{~J} / \mathrm{kg} \mathrm{K}$ for LDF, PB1, PB2 and PB3. Moreover, the influence of density of the investigated materials on their specific heat was not found. The only exception was OSB which was characterized by the specific heat of ca. $1550 \mathrm{~J} /$ $\mathrm{kg} \mathrm{K}$, and it was ca. $100 \mathrm{~J} / \mathrm{kg} \mathrm{K}$ higher when compared to other panels.

Acknowledgments The work was financially supported by the National Science Centre as the 2011/01/ B/NZ9/03169 Research Grant.

Open Access This article is distributed under the terms of the Creative Commons Attribution 4.0 International License (http://creativecommons.org/licenses/by/4.0/), which permits unrestricted use, distribution, and reproduction in any medium, provided you give appropriate credit to the original author(s) and the source, provide a link to the Creative Commons license, and indicate if changes were made.

\section{References}

Baryeh EA (1997) Thermal properties of Odum chipboard. J Appl Sci Technol 1\&2:58-62 
Carvalho L, Martins J, Costa C (2010) Transport phenomena. In: Thoemen H, Irle M, Sernek M (eds) Wood-based panels. An introduction for specialists. Brunel University Press, London, pp 123-176

Chapman KM (2006) Wood-based panels: particleboard, fibreboard and oriented strand board. In: Walker JCF (ed) Primary wood processing. Principles and practice, 2nd edn. Springer, Dordrecht, pp 427-475

Czajkowski Ł, Olek W, Weres J, Guzenda R (2016) Thermal properties of wood-based panels-thermal conductivity identification with inverse modeling. Eur J Wood Wood Prod. doi:10.1007/s00107016-1021-6

Ghazi Wakili K, Binder B, Vonbank R (2003) A simple method to determine the specific heat capacity of thermal insulations used in building construction. Energy Build 35:413-415

Gupta M, Yang J, Roy C (2003) Specific heat and thermal conductivity of softwood bark and softwood char particles. Fuel 82:919-927

Irle M, Barbu MC (2010) Wood-based panel technology. In: Thoemen H, Irle M, Sernek M (eds) Woodbased panels. An introduction for specialists. Brunel University Press, London, pp 1-94

Kamke FA, Zylkowski SC (1989) Effect of wood-based panel characteristics on thermal conductivity. For Prod J 52:75-83

Kawasaki T, Kawai S (2006) Thermal insulation properties of wood-based sandwich panel for use as structural insulated walls and floors. J Wood Sci 52:75-83

Kosny J, Asiz A, Smith I, Shrestha S, Fallahi A (2014) A review of high R-value wood framed and composite wood wall technologies using insulation techniques. Energy Build 72:441-456

Li KY, Fleischmann CM, Spearpoint MJ (2013) Determining thermal physical properties of pyrolyzing New Zealand medium density fibreboard (MDF). Chem Eng Sci 95:211-220

Menczel JD, Judovtis L, Prime RB, Bair HE, Reading E, Swier S (2009) Differential scanning calorimetry (DSC). In: Menczel JD, Prime RB (eds) Thermal analysis of polymers. Fundamentals and applications. Wiley, Hoboken, pp 7-239

Nanassy AJ, Szabo T (1978) Thermal properties of waferboards as determined by a transient method. Wood Sci 11:17-22

Piot A, Woloszyn M, Brau J, Abele C (2011) Experimental wooden frame house for the validation of whole building heat and moisture transfer numerical models. Energy Build 43:1322-1328

Sonderegger W, Niemz P (2009) Thermal conductivity and water vapour transmission properties of wood-based materials. Eur J Wood Wood Prod 67:313-321

Taylor JR (1997) An introduction to error analysis. The study of uncertainties in physical measurements, 2nd edn. University Science Books, Sausalito

TenWolde A, McNatt JD, Krahn L (1988) Thermal properties of wood and wood panel products use in buildings. Report DOE/USDA-21697/1 ORNL/Sub/87-21697/1, Forest Service, Forest Products Laboratory, Madison, WI

Upton B, Miner R, Spinney M, Heath LS (2008) The greenhouse gas and energy impacts of using wood instead of alternatives in residential construction in the United States. Biomass Bioenergy 32:1-10

Ward RJ, Skaar C (1963) Specific heat and conductivity of particleboard as functions of temperature. For Prod J 13:31-38

Wolfinger MG, Rath J, Krammer G, Barontini F, Cozzani V (2001) Influence of the emissivity of the sample on differential scanning calorimetry measurements. Thermochim Acta 372:11-18

Zhou J, Zhou H, Hu C, Hu S (2013) Measurements of thermal and dielectric properties of medium density fiberboard with different moisture contents. BioResources 8:4185-4192 